\title{
Communication of the Public Authorities and Self- Governmental Organizations: Challenges of the Digital Society
}

\author{
Valentyn Orlov $^{{ }^{*}}$, Victoriia Poliakova ${ }^{2}$, Valentyna Shylova ${ }^{l}$, Alina Kuzmych $^{1}$, and Olena Leshchenko ${ }^{3}$ \\ ${ }^{1}$ State University of Economic and Technology, Kryvyi Rih 50086, Ukraine \\ ${ }^{2}$ Executive Committee of Kryvyi Rih City Council, Kryvyi Rih 50050, Ukraine \\ ${ }^{3}$ Kryvyi Rih foundation of the future, non-governmental organization, Kryvyi Rih 50000, Ukraine
}

\begin{abstract}
The article actualizes the problem of communicative interaction between public authorities and self-governing organizations as stakeholders of civil society. The understanding of the essence of selfgovernment, typology of self-government organizations is generalized; the experience of separate legal systems on maintenance of proper communications of the power and self-government organizations in the conditions of development of digital society is studied. The research is aimed at solving the scientific problem of substantiating the conceptual foundations of building public communication systems of government and self-government organizations through the creation of technological platforms for constant constructive dialogue of self-government organizations with local authorities and local government. It is concluded that there are systemic obstacles to communication between the government and civil society. Overcoming such obstacles will ensure a qualitatively new, partnership nature of communication between government and society. The article for the first time raises the issue of creating platforms for communication between the government and self-governing organizations to ensure the participation of citizens in public administration decisions. The results of the study can be the basis for the formation of a new paradigm of the relationship between public authorities and self-governing organizations.
\end{abstract}

\section{Introduction}

The problem of communication between government and society is original and was solved in accordance with specific historical conditions of society based on two aspects - political and philosophical vision of the need for such communication and communicative capabilities of society (tools of communicative interaction), which technologically corresponded to the level of social relations, tangible and intangible culture, the nature of the political system, etc.

With the transition to a digital society, the technological conditions of the communication process have greatly improved; digital technologies have virtually removed the communication barriers that previously existed given the level of technological development of society. Examples of such progress are new definitions of the science of public administration such as e-government, smart state, state in the smartphone, which define the technological essence of the new stage of development of public administration.

However, as practice shows, technology alone does not solve the problem of communication barriers in the "power-society" chain. They significantly change the nature and methods of such communication, encourage the government to determine the challenges of the digital society, but do not change the main contradiction between the authoritarian nature of government and state monopoly in this area, and trends in self-government. These contradictions consist not only in the replacement of centralized structures with decentralized ones, but also in changes within the subject of public administration itself. We mean the involvement in the decision-making processes and governance mechanisms of other stakeholders of civil and, consequently, digital society, which should become not just consumers of management services, but direct participants in management processes.

\subsection{Related Work}

\subsubsection{Self-government as the logic of social development}

The logic of social transformations in the age of digital society is determined by the gradual movement towards civilized forms of democracy, which, in contrast to the era of the crisis of representative democracy, involve broad involvement of citizens in the decision-making process. Thus, representative democracy in the digital age is increasingly saturated with elements of direct democracy.

Although these trends are more relevant to developed representative democracies, there are successful examples of the expression of political will for such reforms in the post-Soviet countries. In 
particular, in Ukraine, where in January 2021 the parliament adopted the Law of Ukraine "On Democracy". This law actually fills the legal vacuum that has arisen in the country as a result of the recognition by the Constitutional Court of Ukraine that the law "On the All-Ukrainian Referendum" adopted in 2012 contradicts the Constitution. This law not only restores the mechanism of democracy through a referendum, but also allows for the initiation of referendums on the repeal of laws or their individual provisions. From the point of view of our research, it is interesting that political parties and public organizations can initiate a referendum.

Another innovation in the legislation is that electronic procedures, including electronic voting, are also being introduced for the referendum. To this end, the bill, based on the study of foreign legislation and the experience of its application to electronic voting, primarily in European countries, provides for the creation of an automated information and analytical system.

It is also interesting that this is the first bill in a series of laws on democracy. Bills have already been prepared and submitted to the parliament on the mechanism of local referendums, popular legislative initiative, the possibility of recalling any official or deputy by early termination of their powers, the possibility of vetoing a law or any normative act of local self-government, implementation of the mechanism of consideration and decision-making on the basis of electronic petitions and a number of others.

The deepening combination of the norms of representative democracy with the norms of direct democracy implies an increase in the volume of communication contacts and the quality of public communication. Increasingly, citizens are taking the initiative in the communication process, and their intermediaries in this process are increasingly organized by civil society - self-governing organizations. Thus, we see the acquisition of broader subjectivity by self-governing organizations that are interested in the implementation of public initiatives and in the broad advocacy of the interests of citizens in the process of exercising power.

This process is long, and the agents of the influence of citizens on public power, peoples, as the only source of power in democratic forms of political regime, are various institutions of civil society, which are more organized and better prepared for such a mission.

All these stakeholders are united by one common feature that distinguishes them from others, including citizens - they are organized (primarily motivated, that is united by a common purpose and have the appropriate resources), and in addition, also selfgoverning (that is have an internal structure that differs significantly from the mechanism of the state and in essence tends more to local self-government).

Against the background of such trends, the research interest in such organizations is quite understandable, as their phenomenon and role in political and public administration processes, and even more so in the processes of communication with the authorities, is insufficiently studied.
Moreover, the process of state interaction with these stakeholders of change is important, because in modern conditions communication problems are a serious obstacle to the implementation of selfgoverning organizations in the legal field of public administration and their institutionalization as actors representing citizens in state-building processes.

The study of scientific works on the spread of direct democracy in the world as a whole and the communication of self-governing organizations with the government, in particular, allowed us to draw a number of interesting conclusions that formed the basis of this study.

First of all, we should turn to the basic things that serve as a goal, a strategy for social development, and which govern the communication between government and civil society as a tool to achieve the goal. All state power comes from the people. This is the basis of the Swedish management system. These are the constitutional definitions of the basic principles of direct democracy, which determine the nature of a democratic political regime. Thus, the Swedish Constitution stipulates that everyone has the same rights and is free to study how politicians and public institutions exercise their power. In the Constitution of Ukraine, this provision is implemented through the thesis that the only source of power in Ukraine is the Ukrainian people. He has full power, but delegate's part of his powers to other bodies or officials who, on his behalf and in his interests, exercise these powers in the manner and within the limits prescribed by constitutional norms.

Some constitutional and legal systems also enshrine the principle of decentralization of power, which, in our opinion, has a common vector with the introduction of direct democracy. Decentralization is determined by direct democracy and develops forms of government in which self-government is a key principle of local government.

It is worth noting the opinion of Tony Porter and Karsten Ronit, who consider self-government an important alternative to government regulation. At the same time, they rightly note that self-governing subjects are rarely completely autonomous from state power [1, p. 41-72].

Indeed, the current practice of public administration in the context of self-government and decentralization of power does not distinguish between self-government and the state definitively. They are interacting elements of a single mechanism of public administration, which participate in the processes of exercising power and a priori communicate with each other. The essence of these two elements of public power is that they received it as a result of legitimizing the political choice of the people (the population of a certain administrative-territorial unit).

At the same time, we should agree with the authors, who conclude that, the function of the state to activate self-governing mechanisms at different stages of the political and public administration process [1].

The state is interested in the development of selfgoverning structures, as they naturally ensure the 
functioning of public administration structures at the local level of public authority.

Against this background, in the digital society there is a process of updating the communications of government and society through its agents - selfgoverning organizations, which is manifested in the significant digitalization of the communicative process - from direct expression of will.

In her study, Kieron O'Hara characterizes digital reality as capable of influencing the political subsystem of society. According to her, digital technologies transform the material state of mankind and the benefits of such transformations may be political. Exploring the concept of digital modernity, in particular the possibilities of digital network technologies, she draws attention to the fact that the narratives of digital modernity shape reality through actors who make political, authoritative decisions [2].

From this point of view, public communications act as a mechanism for citizen participation in the management of public affairs. According to Tina Tomazic and Katja Udir Mišič, social media is one of the tools for activating the position of citizens in modern society. They draw attention to their role in communication between Parliament and citizens in terms of ensuring the self-government of local authorities. In their study, the authors present interesting results of a survey on the use of social media on the websites of the parliaments of the Member States of the European Union. 57\% of such entities in 2016 already used Facebook, Twitter, YouTube, video streaming, calendar and RSS (Rich Site Summary) messages [3].

The technologization of the process of exercising political power and the participation of civil society and citizens directly in this process is also manifested in such a technological tool as electronic elections. In this regard, the position of Dr. Silvano Moeckli, who considers digital technology as a tool of political communication through the use of the Internet in election campaigns to embody the political will of citizens [4], deserves attention.

Thus, self-government is a key characteristic of local government structures in the digital society. The self-governing nature of these structures and their focus on interaction with civil society determine the process of their communication with citizens and the role of mediator in relations with the state. In these communications, a key role is played by the technologies of the digital society, which determine the methods of communicative interaction between government and society.

\subsubsection{Our Contribution}

This article presents the results of the analysis of the problem of communication between public authorities and self-governing organizations against the background of the development of the digital society. Based on the generalization of observations and based on their own experience of communication with local authorities, the authors critically considered the practice of building public communications in the subsystem "public authorities - self-governing organizations". Our contribution is to clarify the essential characteristics and classification of selfgovernment organizations, identifies contradictions in communication between government and civil society, and clarifies the functions of self-government organizations in ensuring communication between government and citizens, government and society.

The article proposes a new solution to the problem of communication between the government and civil society agents in order to strengthen the opportunities for involving citizens in decision-making processes in the public sphere.

\subsubsection{Paper Structure}

The presented text of the article is organized in such a way that first the problem is posed in general, reveals the essence and characteristics of communication between government and self-governing organizations, the conditions in which processes take place, and then reveals the specifics of self-government in the public sphere as a phenomenon, and self-governing organizations and ways of forming models of public communication between the government and selfgoverning subjects of civil society.

\section{Background}

\subsection{Specifics of self-government in the public sphere}

In scientific works V. Averianov, G. Atamanchuk, M. Baitin, L. Grygorian, R. Dal', L. Kask, A. Kim, V. Lisnychyi, R. Maksakova, N. Nyzhnyk, M. Orzikh, V. Sirenko, M. Studienikina, A. Selivanov, A. Trachuk, M. Tepliuk, P. Usmanova, A. Yugov, the term "Public Power" is an element of scientific research and to this day has not received an unambiguous interpretation.

So R. Maksakova [5] defines the term "public authority" as the activity of local governments at the regional and municipal levels, in cooperation with the government and government at the national level, and emphasizes that the term is related to the activities of individuals and legal entities in the performance of their public duties and functions. V. Lisnychyi [6] reflects the term "public power" as a state organization of political life, carried out with the help of the state apparatus. Also, in his works, V. Lisnychyi notes that the state in the exercise of public power is based on material and moral impulses that affect the effectiveness of the exercise of power.

In Volume 6 of the Legal Encyclopedia [7] the term "public power" is identified with the term "democracy" and defines certain types of public power, they include: democracy, state power, local government. A similar opinion is shared by O. Skakun [8], who notes that public authority is the so-called "voice" of society and has open principles of its activities.

In his scientific works, A. Kim [9] clearly distinguished between the concepts of "public power", "state power" and "public power" and noted that public 
power is born of political relations. In turn, L. Grygorian [10] also distinguishes between the concepts of "public authority" and "public authority".

A. Yugov [11] considered the term "public authority" as a system of public and public participation in resolving matters concerning their territories and in resolving issues of public interest. The scholar emphasized that public power is a mass social power, which is described and supported by law.

Investigating the work of A. Selivanov [12], we conclude that he considered public power as a dual phenomenon: as state power and as the power of local government (municipal power).

According to M. Tepliuk [13] is directly a power exercised in the interests of subordinate bodies or organizations that represent public power and are public power.

Thus, the term "public authority" can be interpreted in terms of the mechanism of implementation, the nature of existence, the nature of functioning. The fact that there is currently no unequivocal opinion on the interpretation of the term "public authority" is also confirmed. Summarizing the views of scholars, we can determine that public power is a modern form of public power and is the main organizer of public, political and state interaction, which arose to address socially significant issues and governance processes.

Turning to the terminology of the concept of "selfgoverning organization", we note that the theme of the essence, formation, functioning, development of selfgoverning organizations in Ukraine in their scientific works studied by such Ukrainian scientists as $\mathrm{O}$. Bielokurova, G. Zelen'ko, M. Lirchuk, A. Matviichuk, M. Obushnyi, M. Stavnychuk, O. Sungurova, V. Tsvyh and $\mathrm{Yu}$. Shemshuchenko.

Defining the term "self-governing organizations" consider the opinion of the scientist M. Lirchuk. In his scientific works, he notes that self-governing organization is the highest form of civic non-political associations, which are characterized by the establishment of standards, norms and rules of its members - various social actors, and establish mechanisms of interaction with the state.

According to A. Matviichuk [14] self-governing organization is an element of civil society, which must have constructive cooperation with the state on the regulation of relevant activities and has a nongovernmental nature.

In general, agreeing with the authors of the analyzed works, we pay attention to the specifics of their communication with the authorities, which follows from the self-governing nature of such entities.

Thus, it can be determined that self-governing organizations are institutions that are created to meet public interests and needs, to organize the public, to promote the development of one or more activities of society.

If we consider the content of communication processes, we should dwell on the approach of $\mathrm{O}$. Sungurov [15], who described seven types of communication process between public authorities and self-governing organizations:
1. The model of the gardener provides acceptance of organizational and legal bases at the state level;

2. Partnership model provides for parity of public authorities and self-governing organizations;

3. The architect's model provides for the initiation and involvement of self-governing organizations in the creation of new structures of public authorities.

4. The paternalistic model provides for the autonomy of self-governing organizations.

5. The model of drive belts, characterizes the dominance of the interests of public authority over the interests of self-governing organizations.

6. Model of ignoring, which comes into force when partial or complete ignoring of self-governing organizations by public authorities.

7. The model of struggle against the enemy presupposes public disobedience and confrontational relations between self-governing organizations and public authorities.

An important theoretical and methodological value is also the concept of O. Belokurov [16], who pointed to three models of interaction of self-governing organizations with public authorities, to which he refers:

- Normative model (liberal model, full-fledged interaction);

- Legitimation model (participation of selfgoverning organizations in the development of territories);

- Instrumental model (active involvement of selfgoverning organizations in solving socially significant problems).

It should be noted that self-governing organizations do not have the power and are not a body of public authority, although they operate in the public sphere, because they are part of civil society. Therefore, the term "public authority" distinguishes elements of the public sphere that are institutionalized in government (eg., local government) from self-governing organizations that are not endowed with public authority: associations, associations of apartment building co-owners, public organizations and associations, political parties, trade unions and other independent institutions.

The development of civil society in Ukraine and the strengthening of the democratic system led to an increase in the level of conscious participation of citizens in state-building processes, which was preceded by a number of reasons: the state creates such social relations, where objects and subjects, seeks to increase its role and importance in the public sector. Thus, communication processes are an important aspect of a modern democratic society and enable:

- The presence of a certain stabilizing tool in society;

- Openness of the government to the public through self-governing organizations;

- Participation of self-governing organizations in the decision-making process.

- Participation of self-governing organizations in the development and discussion of draft regulations, as well as the initiation of such work; 
- Control over the observance of norms and laws by the subjects of the relevant relations;

- Creating a development strategy for any area;

- Participation of self-governing organizations in the development and discussion of draft regulations, as well as the initiation of such work;

- Involvement in state-building processes.

Based on the above, we can distinguish four stages of communication between self-governing organizations and public authorities, namely:

1) Information process (access to information, mutual information);

2) Counseling (discussion);

3) Dialogue (two-way communication, cooperation);

4) Partnership (division of responsibilities between the two parties to the process).

Thus, an active dialogue between self-governing organizations and public authorities creates a positive environment for the improvement of existing processes and actions, as well as creates a positive environment for society, which leads to:

- Decision-making with a focus on socially significant needs;

- Increasing public confidence in public authorities;

- Reduction of the corruption component in public authorities;

- Improving the quality of public services;

- Successful development of any territory.

Thus, we are convinced that a significant part of research interest in this issue is focused on studying the mechanisms of functioning of self-governing organizations in the context of their involvement in the process of public authority. In this process, in a digital society, an important place is occupied by communicative interaction between participants in the process.

\subsection{Communication of public authorities and self-governing organizations}

Communication in the context of digital social transformations is one of the most important tools of public administration given the technologization of society and social connections within it. It is especially important for us to consider the essence of this process in the system of public power - self-governing organizations.

Analyzing the legal and managerial aspects of state policy in the field of cooperation between civil society and the executive, $\mathrm{O}$. Turii determines that civil society as a self-governing institution plays a transformational and protective function in preventing the threats of authoritarianism. According to the author, volunteer, charitable and voluntary movements are the tools for implementing such functions, and the example of the Ukrainian state in recent years is another proof of this. The author emphasizes the need to create effective mechanisms for integrating the communicative efforts of government and society in solving common problems [17].
Indeed, the lack of communication entails an imbalance in the unity of the holistic formation of power as an organic phenomenon. It is organic, because the current system of power is a rather subtle matter, absolutely sensitive to challenges and threats, and therefore one that no longer acts as a mechanism, but as an organism. Such organicity makes the processes of information exchange extremely important. Because they connect the body and integrate its capabilities.

M. Tokar analyzes the potential of interaction between authorities and public organizations in the development of civil society and concludes on the need to integrate the experience, initiatives and capabilities of these actors, draws attention to the state-building importance of close cooperation between them [18].

Of course, such integration must be technological. That is to have a technological basis for its implementation. Such technologies are offered by the digital society. The emphasis is on electronic communications, which are becoming comprehensive, quite accessible and, most importantly, effective.

O. Goncharenko and L. Neskorodzhena give an example of electronic communication between the government and self-governing organizations in the field of culture; conclude that this is a consequence of a creative approach to public administration processes. According to them, public associations in the field of culture perform representative and protective functions, as they have the opportunity to create charitable organizations to finance cultural programs, participate in the development of regulations on cultural activities, promote a stable dialogue between the government and such a specific area., which is the culture [19].

Agreeing with this statement, we can assume that the creative nature of public communication affects the communicative processes in other spheres of public life. This is satisfied by the experience of European countries, where integrated models of communicative interaction between government and society have been formed. This experience is extremely valuable for young democracies that have just embarked on the path of digital transformation of social organization.

S. Lizakowska studies the specifics and conditions of effective interaction between civil society and public authorities in EU member states. It establishes that cooperation based on common interests and values of citizens and social groups with public authorities is an effective model, tested by the experience of European democracy [20].

It should be emphasized that the thesis of common interests is a key, system-forming factor of such interaction. One can see from the recent events in Russia, related to mass protests against the current government, that one of the reasons for the protest mood is the lack of a common vision of the country's development prospects between the current government and civil society. In Russia, civil society, despite its low institutionalization of the government and the practical absence of the opposition, nevertheless actively influences the government. The latter does not want to communicate with the opposition other than through repression. 
What does the experience of the totalitarian system of governing Russia show? First of all, that in the political sphere this state continues to remain in the past, without passing into the digital age with its social transformations. And it's not about technology, but about the fact that, unfortunately, they do not determine social and political change. It is this contradiction that unbalances the political system and slows down the development of a new type of social relations in Russia. And it is necessary to constantly improve communication in the system of power relations. This is what many researchers say.

For example, the scientific work of P. Shpyha and $\mathrm{M}$. Khmelnytska is about improving and ensuring the effectiveness of the process of interaction between government and the community through the development of a modern information and communication system. The authors argue that the purpose of public administration is to organize the joint activities of people, their individual groups and social organizations, ensuring coordination and interaction between them [21].

Thus, for the purposes of our study, it is important to identify the contradictions that arise in the communication of self-governing organizations and government:

- Contradictions between the public nature of the goals of the state and the private interests of representatives of individual self-governing organizations, based on differences of opinion on the prospects for society;

- Contradictions between the powers of public administration bodies and the public nature and volunteer nature of the activities of self-governing entities;

- Contradiction between the interests of specific representatives of public political power and the views of the general population;

- Contradictions between the broad possibilities of the digital society in creating communication channels for interaction with civil society and the limited methods of government in the dissemination of information messages;

- Contradictions between the ubiquity of public power and the limited nature of authoritarian communication with society;

- The contradiction between the widespread development of information technology and the lack of willingness of the authorities to use their capabilities in communication with the public structure;

- Contradictions between the technological nature of the process of communication between the authorities and political ways of interaction with civil society.

These contradictions are in varying degrees inherent in the process of communication between government and self-governing organizations in any social system. The degree of contradiction depends largely on the political perfection of power and the development of democratic institutions.

\subsection{Formation of communicative models of interaction: the experience of Ukraine}

Taking into account the existing systemic contradictions in the communication between the government and civil society allows not only to see the causes of the problems, but also to correct the mistakes of the government in its relations with stakeholders. This is especially important at the level of individual local communities, where the most relevant decisions are made, where communication seems to have the least barriers, but no fewer problems.

Two processes are important backgrounds for Ukraine in the transition to digital society:

- Decentralization;

- Decommunization.

How do these processes affect the formation of a national culture of communicative interaction between government and society?

Decentralization provides local authorities with more material resources to address local issues. It is clear that some of these resources can be used to establish effective communication with stakeholders. Indeed, the communication influences of local authorities have recently become more organized due to the concentration of financial resources. However, has the new government effectively disposed of these resources? Unfortunately, there are in most cases not. The main direction of the funds allocated for communication is spent on the so-called coverage of the activities of local authorities, local governments. Moreover, the nature of such coverage is mostly personalized. In other words, the authorities do not communicate in order to get feedback from the population, but in order to maintain their positive image. From the point of view of strategic communications, this is ineffective, because the image formed as a result of one-way communication is unstable, and on the other hand, this process will increasingly require increasing investment.

In addition, the methods of involving citizens and their representatives - self-governing organizations - in dialogue with the authorities are also one-sided, in the form of public councils with the authorities, which perform an advisory function and are very limited in the discussion process, especially decision-making, system of local government.

And here is the time to mention decommunization. Since a significant part of regional and local political elites tend to the vestiges of the communist past, they are the bearer of the worldview formed in the past, it is quite logical that the methods of communication of the authorities tend to this past. And this is against the background of new information technologies and the development of modern information space.

Thus, the problem of the current state of power communications in Ukraine is the lack of a holistic strategy, future-oriented and mentally formed on the European models of communicative interaction.

Such a one-sided assessment of the media as a tool of political and managerial interaction hinders the development of elements of civil society at the local level. Such communication is sporadic, mediated by 
the interests of the authorities, completely devoid of elements of feedback.

P. Krister B. Anderssona, K. Chang, A. MolinaGarzónb in their study Voluntary leadership and the emergence of institutions for self-governance draw attention to such an important aspect as the selflessness of leadership, which is important in sparse communication. Their conclusions boil down to the fact that the effect of selfless leadership in selfgoverning organizations is much greater than in bureaucratically organized systems of power [22].

In our opinion, the communication activities of public administration are not identical to political communication, which is one-sided and manipulative. We see public communication, especially of local authorities, as a tool for building relationships with citizens that have long-term consequences, rather than situational political commitment based on a high level of trust in government. This model of public communication is focused on long-term transparent dialogue, publicity of discussions, and debatable nature of discussion of contradictions, which comprehensively implements the mechanism of citizen participation in local affairs management, independent, adapted to realities, public interest-oriented system of communicative interaction.

There are several options for solving the problem from an information hub, an Internet portal that would become a communicative platform for dialogue between government and public self-government organizations to standardize the results of local referendums (polls) and search for direct democracy technologies in a digital society.

The search for forms of such institutions is characteristic of young democracies, where the paradigm of social communication is gradually shifting from one-sided socialization to more interactive. As a result, freedom of speech develops; the public can actively communicate with the government and vice versa. Since the government is almost incapable of communicating with all social groups, it makes sense to use the experience of implementing the concept of social institutions as a communication center between the government and its public, which in Surabaya is called Kelompok Informasi Masyarakat (KIM) [23].

\section{Conclusion}

The system of communication interaction in the public sphere is a complex, dynamic phenomenon that is transformed in accordance with the content and nature of social relations. In the digital society, such transformations change not only the forms of communicative interaction, but also significantly adjust the nature of the relationship between government and civil society.

The tendencies of self-government that accompany the development of social systems in the digital society actualize the problem of interaction of political power with self-governing organizations that act as stakeholders of power and mediate its relations with citizens.
Self-governing organizations are a fairly structured phenomenon, the diversity of manifestations of which gives grounds for the conclusion that they can be classified. Despite such diversity, self-governing organizations, as autonomous entities, are able to be the subjects of political interaction, to be involved in the processes of public administration and to oppose the authorities. Such involvement in political and managerial processes allows us to conclude that their communication with the authorities is conditional.

Research interest in the problems of communicative interaction between the state and self-governing organizations is justified by the prospects of developing decentralized forms of democratic political regime with the tools of direct democracy, which balance and contribute to the renewal of public governance.

The practice of relations between the government and self-governing organizations requires understanding and scientific substantiation. The article makes such an attempt and proposes a new partnership type of relationship between these entities, as well as possible forms of interaction between them in the practice of the new public government.

The practical orientation of this study is revealed on the one hand by the interaction of civil society actors with the government, and on the other hand - requires built-in interactive relationships between governments and public authorities on a qualitatively new basis and in new social conditions.

Prospects for further research in this area may be the search for and scientific justification of forms and methods of institutional interaction between selfgoverning organizations and government agencies, the study and generalization of the experience of their participation in public administration decision-making processes.

The world experience of building models of communicative interaction between government and the public sector can be adapted to the conditions of young democracies with their post-Soviet rudiments and specific legal systems. The choice of such models is a good practice of good governance as a philosophy of modern public administration.

\section{References}

1. T. Porter, K. Ronit, Self-Regulation as Policy Process: The Multiple and Criss-Crossing Stages of Private Rule-Making Policy Sciences 39(1), 32 (2006), doi:10.1007/s11077-006-9008-5

2. K. O'Hara, The contradictions of digital modernity. AI \& SOCIETY 35, 197-208 (2020), doi:10.1007/s00146-018-0843-7

3. T. Tomazic, K. Udir Mišič, Parliament-citizen Communication in Terms of Local Selfgovernment and Their use of Social Media in the European Union (2019), doi:17.4.1057-1079

4. S. Moeckli, So functioning directly Democracy Stuttgart, 2018 
5. R. Maksakova, Constitutional and legal problems of organization and implementation of the constituent power in Ukraine, Zaporozhye, 2012

6. V. Lisnychyi, Conceptual foundations of political science: theory and history, method and didactic materials, Kyiv, 2001

7. Yu. S. Shemshuchenko (ed.), Legal encyclopedia: in 6 volumes (Kyiv, 2013)

8. O. Skakun Theory of state and law (encyclopedic course) (Kharkiv, 2005)

9. A. Kim, Gosudarstvennaya vlast i narodnoe predstavitelstvo v SSSR, Tomsk, 2015

10. L. Gregorian, Democracy in the USSR, Moscow, 2012

11. A. Yugov, Constitutional principles of public power: the Russian dimension, Moscow, 2015

12. A. Selivanov, Public power and the citizen in the conditions of application of judicial administrative jurisdiction (problems of theory and practice), Law of Ukraine, 8, 28 (2016)

13. M. Tepliuk, Public power in Ukraine: definition and constitutional and legal nature, Law of Ukraine, 5, 6-22 (2019)

14. A. Matviichuk, Self-governing organizations as elements of civil society and principles of their creation, Gileya: scientific bulletin, 83, 397-401 (2014)

15. A. Sungurov Models of interaction of state authorities and structures of civil society: Russian experience, 9 (2018)

16. N. Yargomskaia, E. Belokurova, M. Nozhenko, Why NGOs and authorities need each other. Models of interaction in the regions of the North, Public policy: issues of soft security in the Baltic region, St. Petersburg, 2014, ed. MB Gorny

17. O. Turia, State policy in the field of civil society cooperation, executive and local government: legal and managerial aspects. Public Administration Aspects, 6, 38-44 (2018). doi:10.15421/151837

18. M. Tokar, Potential of interoperability of the state, local self-government and public organizations in Ukraine: integration of experience, initiatives, opportunities, Efficiency of public administration, $64(2020)$

19. O. Goncharenko, L. Neskorodzhena, Selfregulation of culture: the role of public associations and electronic communication, Bulletin of the National Academy of Management of Culture and Arts, 4, 121-126 (2018)

20. S. Lizakowska, European standards of interaction between public authorities and civil society organizations, Public Administration and Regional Development, 8, 422-443 (2020)

21. P. Shpyha, M. Khmelnytska, Digital communications between government and community: problems, risks, barriers. Public Administration: Theory and Practice. 2, 13-20 (2019). doi: 10.36030-2311-6722-2019-2-13-20
22. P. Krister, B. Anderssona, K. Chang, A. MolinaGarzónb Voluntary leadership and the emergence of institutions for self-governance PNAS, Proceedings of the National Academy of Sciences of the United States of America, 44, 117 (2020)

23. Dinas Komunikasi dan Informatika Kota Surabaya, Buku Panduan KIM Kota Surabaya, 2017 